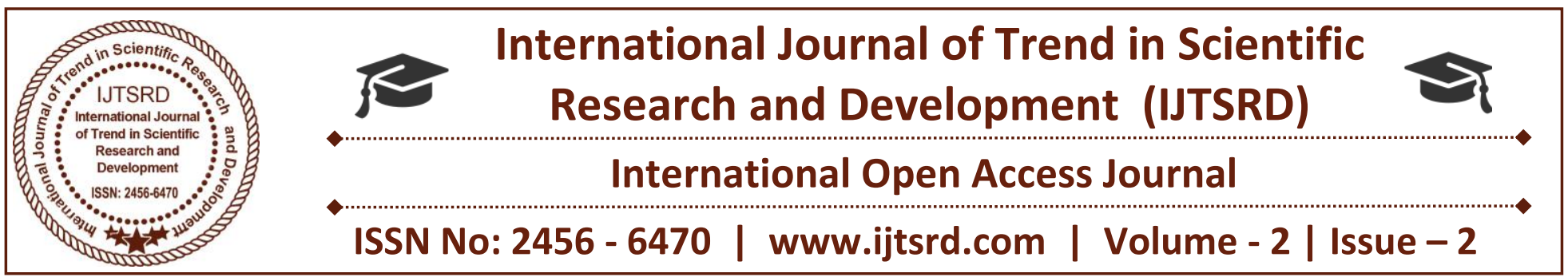

\title{
Effectiveness of Erythinae variegata juice on dysmenorrhoea among final year nursing students
}

\begin{abstract}
A. Rajarajeswari
M.sc (N) PhD, PhD Scholar

(Meenakshi University) HOD

in OBD Department, Vinayaka

Mission's College of Nursing,

Puducherry, India
\end{abstract}

\author{
Dr. G. Muthamilselvi \\ Principal, Vinayaka Missions \\ College of Nursing, \\ Puducherry, India
}

\author{
Dr. C. Susila \\ Principal, Billroth College \\ of Nursing, Chennai, \\ Tamil Nadu, India
}

\section{ABSTRACT}

Background: Dysmenorrhea refers to the occurrence of painful menstrual cramps of uterine origin. Dysmenorrhea has been estimated to be the greatest cause of time lost from work and school in the India. The study aim was to assess the effectiveness of Erythina variegata juice on dysmenorrhea among final year nursing students (B.Sc \& DGNM).

Methods: A pre experimental research design was carried out in Vinayaka Missions College of Nursing at Puducherry. The 30 sample was selected based on convenient sampling technique. The pretest was conducted by using visual analogue pain scale during menstrual cycle with dysmenorrhea. As an intervention of Erythina variegata juice was given to the same group prior to menstrual cycle on complete 5 days.

Results: After the collection of posttest, the collected data were analyzed by using descriptive and inferential statistics. Results shown that the ' $t$ ' value is 5.133 and ' $P$ ' value is $<0.000$, it's highly significant.

Conclusion: The study found that Erythina variegate juice is more effective for the dysmenorrhea.

Keywords: Erythina Variegata, Dysmenorrhoea, Pain scale.

\section{INTRODUCTION:}

Adolescence is a period of transition from childhood to adulthood. Adolescence is beautiful and tough phase of life. It compasses physical and a psychological change into an adult the period of adolescence for a girl is marked by puberty among the commonly observed problem of health during this pubertal stage is dysmenorrhea which ranges from $60 \%-93 \%$.

Many adolescent reports limitations of daily activities, difficult to perform normal house hold work or college, related activities for a few days during each menstrual cycle. A painful menstruation is the leading cause of lost time, from school, college such as missing college events, and other social activities

Kalyana Murungaiillai is famous in the rural area and in English; it is called as Indian coral tree, or Tiger's claw. Botanical name of the Kalyana Murungaiillai is called as an ErythrinaVarigata. It is a rich source of rare vitamins and minerals with iron, fiber enhances in strengthening bones, Proper function of digestive and kidney daily routine work. The leaves of the kalyana murungai are either crushed or juiced to eradicate menstrual problems, mother's milk secretion, dysentery, diuretic and join pain. The leaves are laxative, diuretic, anti-helminthic and are able to induce milk secretion in a new mother. 


\section{LITERATURE SURVEY:}

It's well recognized that menstruation is a highly emotional experience for adolescence girls. During menstrual period the adolescent girls are suffering from premenstrual symptoms and most of the girls suffering from the dysmenorrhoea problem.

Vaidynathan.D etal.,(2014) conducted survey of ethno medicinal, plants and folklore studies on malayali tribals of vellakadai village a part of shervaroy range in eastern ghats, Tamil Nadu. India during June 2013 to December 2013. A total of 200 species of ethno medicinal plants belonging to 176 general and 74 families were reported with the help of tribal people between the age of $40-75$ years, dwellers provided information regarding the species used as medicine, parts used and mode of preparation, remedies and aliments. They have used 200 plant species for many medical uses, among this more than $40 \%$ of Kalyana Murungai illai used for the treating women's problems like dysmenorrhea, milk secretion, irregularities of periods etc., We are gathered the knowledge regarding folklore of the tribals. The data's were collected by taking photos and interviewed the tribal people.

The investigator's experience with her colleagues with dysmenorrhea had shown that quality of work academic and clinical seems affected. Peer and social interaction were also markedly affected during their menstrual days. This motivated the investigator to research into various methods that reduce the severity of dysmenorrhea in a natural way so as to permit normal activities even during their menstruation.

Based on the findings of previous studies and on the fact that no study of this nature has been conducted in the selected setting. The investigators plan to assess the effectiveness of Erythrina Variegata juice on dysmenorrhea.

\section{STATEMENT OF THE PROBLEM:}

A Pre experimental study to assess the Effectiveness of Erythrina Variegata (Kalyana Murungai) juice on dysmenorrhea among final year nursing students (B.Sc. \& DGNM), Vinayaka Missions College of Nursing at Puducherry.

\section{OBJECTIVES:}

- To assess the pretest level of pain score on dysmenorrhoea among final year nursing students.
- To determine the effectiveness of Erythinavariegata (kalyanamurungai) on dysmenorrhoea among final year Nursing Students.

- To associate the pretest level of pain score with selected demographic variables

\section{METHODS AND MATERIALS:}

The research approach accepted for the study was pre experimental design with one group pretest post-test only design.

The instrument developed and used for the present study consists of two sections Part-I consisted of 12 items related to demographic variables Part-II consisted of visual analog scale for dysmenorrhea administration of ErythinaVariegata.

The content of validity of tool was established on the basis of expert's judgments. The reliability of tool was established by inter rated and inter observer method. The intra class correlation co-efficient formula was used to test reliability of the tool. The reliability of tool was ' $r$ ' $=0.8$. The tool was found to be reliable and feasible.

The final study was conducted from $22^{\text {nd }}$ May to $24^{\text {th July }} 2016$ kirumampakkam Puducherry. Dysmenorrhoea strategy was tested for its effectiveness by pre experimental design with one group pretest and posttest only research design. Convenient sampling technique was used to select the 30 final year nursing students. The pretest was conducted by using visual analogue pain scale during menstrual cycle with dysmenorrhea. As an intervention of Erythina variegate juice was given to the same group prior to menstrual cycle on complete 5 days. After the completion of the posttest, the data gathered were analyzed and interpreted in terms of objectives. Descriptive and inferential statistics were used for the data analyzed.

\section{RESULTS AND DISCUSSION:}

Most $(70 \%)$ of the students were between the age group of 19-21 years. 50\% of the students were attained their menarche at the age of $13-15$ year. Majority $(73.33 \%)$ of the mothers were Hindus. $76.67 \%$ of nursing students residing in rural area. Most (76.67\%) of the nursing students had regular menstrual cycle pattern. $53.33 \%$ of nursing students had the family history of dysmenorrhea. Equal 
distribution of nursing students belongs to the both of information $40 \%$ nursing students were got nuclear and joint family. Regarding the dietary pattern $90 \%$ of nursing students were adopted vegetarian. The highest $(73.33 \%)$ percentage of nursing students were had a 1-3 days of menstrual cycle. Regarding source information through the friends and relatives. $83.33 \%$ of nursing students were practiced any one of the natural remedies. All the nursing students (100\%) had a painful menstruation.

Figure -1 Distribution of pretest level of pain regarding Erythina variegata on dysmenorrhea among final year Nursing Students.

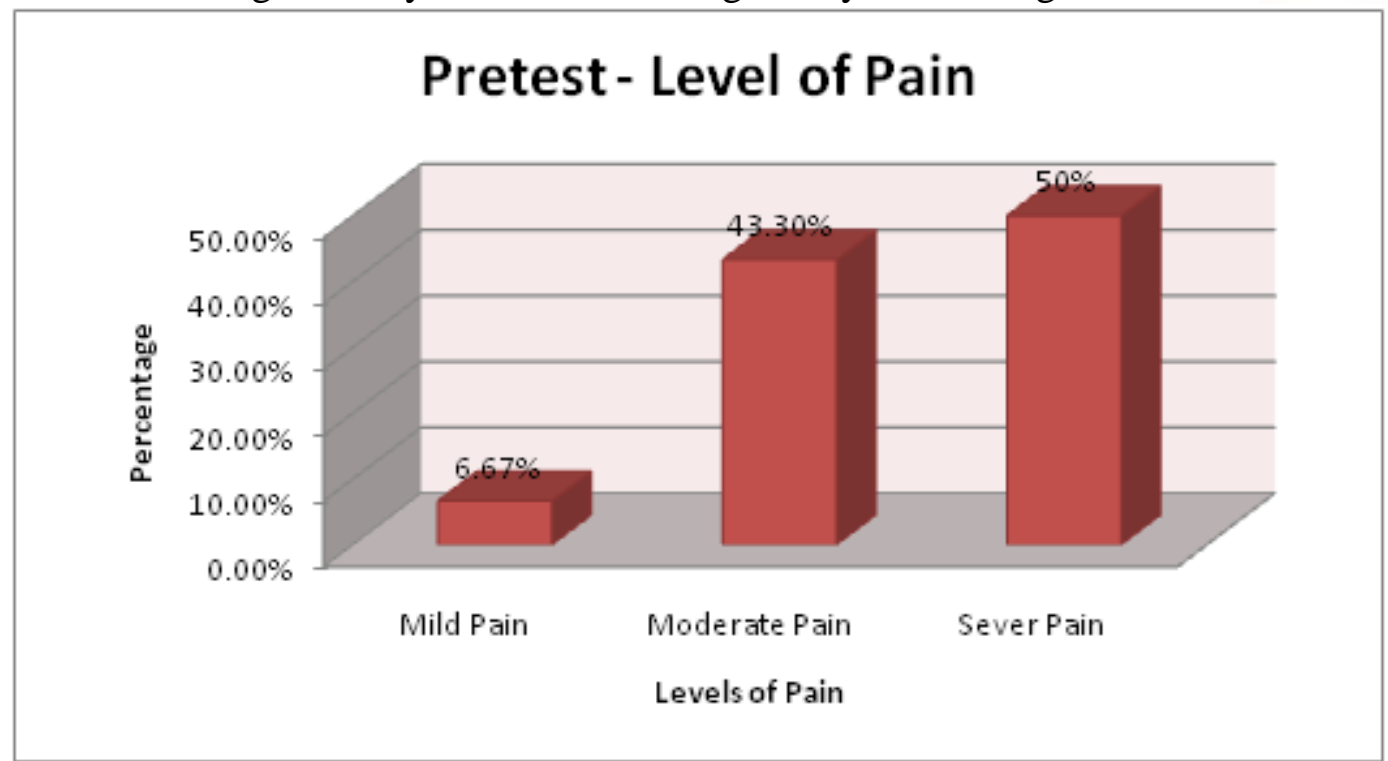

Fig - 1 shows that the pretest level of pain regarding erythina variegata on dysmenorrhea, in that $50 \%$ students had severe pain and $43.30 \%$ of students had moderate pain and only $6.67 \%$ had mild pain.

The pretest of pain mean value is 3.37 and SD is 0.615 comparatively the posttest level of pain mean value is 2.343 and 0.858 and means difference is 1.02 . Hence it's interpreted that the posttest level of pain has got effective score.

Fig - 2: Distribution of comparison of pre and post level of pain regarding Erythina variegata on dysmenorrhea among final year Nursing Students

\section{Comparison of pre and post level of pain}

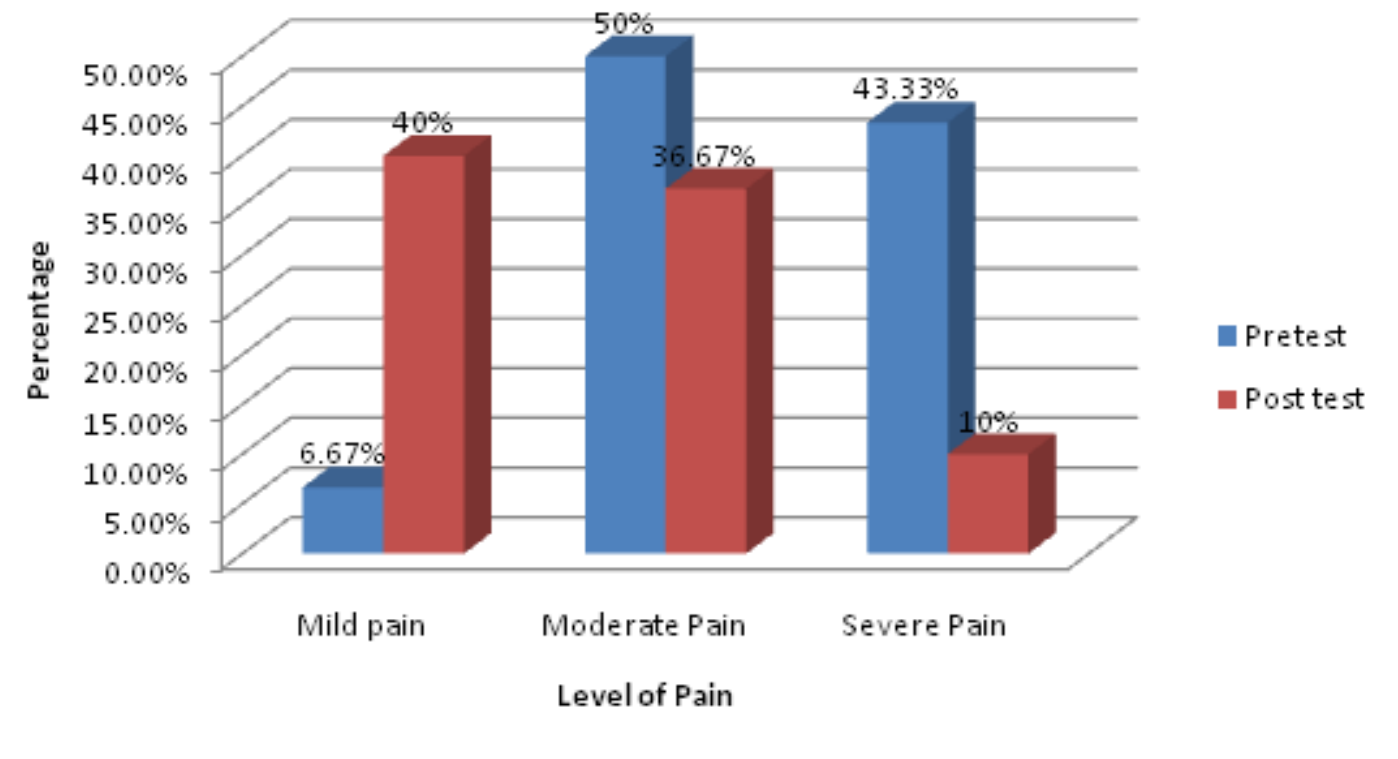


Results shown that in pretest $43.33 \%$ were experienced severe pain were as in posttest only $10 \%$ were experienced severe pain. 50\% of students were experienced moderate level of pain in pretest were as in posttest only $36.67 \%$. Mild pain was experienced in pretest $6.67 \%$ comparatively $40 \%$ in post test

Table -1: Effectiveness of Erythina variegata on dysmenorrhea among final year Nursing Students

\begin{tabular}{|l|l|l|l|l|l|}
\hline Level of pain & Mean & $\begin{array}{l}\text { Standard } \\
\text { deviation }\end{array}$ & $\begin{array}{l}\text { Difference } \\
\text { mean }\end{array}$ & 't' value & 'P' value \\
\hline $\begin{array}{l}\text { Pre and post level } \\
\text { of pain }\end{array}$ & 2.367 & 2.526 & 29 & 5.133 & $0.000 * * *$ \\
\hline
\end{tabular}

Table -1 depicts that the Paired ' $t$ ' test results shown that the Standard Deviation is 2.526 and' $t$ ' value is 5.133 and ' $\mathrm{P}$ ' value is $<0.000$. Hence it's interpreted that the ' $\mathrm{P}$ ' value is highly significant and ErythrinaVariegata juice was more effective. Hence H1 hypothesis is accepted here.

There is no association found between the pretest level of pain with selected demographic variables like age in years, age at menarche, religion, residential area, menstrual cycle, family history of dysmenorrhea, family history of dysmenorrhea, type of family, dietary patterns, duration of menstruation and source of knowledge, duration of menstruation and dysmenorrheal remedies. Hence $\mathrm{H} 2$ hypothesis is not accepted here.

\section{RECOMMENTATION}

A study can be replicated on large sample there by findings can be generalized to a large population.

A true experimental study can be conducted to find out the similarities or difference in effectiveness of Erythrina variegata juice on dysmenorrhea among final year nursing students at VMCON.

* Descriptive study can be conducted to find out the knowledge, attitude and practice regarding Erythrina variegata juice on dysmenorrhea among adolescents.

* An experimental study can be conducted to find out Erythrina variegata juice on dysmenorrhea among adolescents at selected schools.

* An experimental study can be conducted to find out the effectiveness of Erythrina variegata juice for other reproductive problems.

\section{REFERENCE:}

1. Angeline. S. Preethiesther. Dysmenorrhoea. Health action journal. 2010. October; 16(7): 2527.

2. Dr. Shaji J.C. Helen. Controlling Dysmenorrhoea among adolescents girls. Nightingale nursing times. 2012. October; 8 (7): 24-27

3. Gupta .V.M. Adolescents health India journal of public health. June; 1(8): 1-8.

4. Abioye Kuteyiea. The menstrual knowledge and practices among Adolescent girls. Journal of India. December 1(2): 69-78.

5. Mahbubur Rahman.A.H.M etal.. Ethno gynecological disorders of folk medicinal plants used by santhal of Dinajpur District,Bangladesh.Frontiers of Biological and Life sciences.2014.2(3): 62-64 